\title{
Study of Several Aspects of Fishery for Guiding Barrier Fishing Gear in The Coastal Town Palopo
}

\author{
Ridwan Sukimin ${ }^{1 *}$, Danial ${ }^{2}$, Abdul Rauf ${ }^{2}$ \\ ${ }^{1}$ Program Studi Ilmu Kelautan Universitas Muhammadiyah Palopo \\ ${ }^{2}$ Program Studi Manajemen Pesisir Dan Teknologi Kelautan Universitas Muslim Indonesia
}

\author{
Article History \\ Received : June $24^{\text {th }}, 2021$ \\ Revised : June $30^{\text {th }}, 2021$ \\ Accepted : July $12^{\text {th }}, 2021$ \\ Published : July $18^{\text {th }}, 2021$ \\ *Corresponding Author: \\ Ridwan Sukimin, \\ Program Studi Ilmu Kelautan \\ Universitas Muammadiyah, \\ Palopo, Indonesia; \\ Email: \\ rdwnskmn75@gmail.com
}

\begin{abstract}
Fishing is a profession that has long been carried out by humans and is estimated to have been thousands of years old. Sero is one of the many types of fishing gear that is often operated by coastal fishermen, especially in the Palopo City area. Fish, crabs, squids, lobsters, turtles and even estuarine crocodiles are just a few examples of variations in the types of marine life that can be trapped in sero fishing gear. Along with the growth of human population and advances in fishing technology, the level of exploitation is increasing. On the other hand, the carrying capacity of the environment, including fish resources, has limitations. The increasing number of fishing activities accompanied by the reduction of catch targets also causes competition between fishermen to compete for these resources often occurs. These things then motivated the author to conduct a scientific study in the hope that the results of this study can be one of the basis for the preparation of regulations, especially with regard to the use of sero-type fishing gear in Palopo City. The purpose of this research is to examine the existence of sero fishing gear in relation to potential conflicts, business contribution, types of catch, selectivity, and estimated catch to fishing effort. The research method used includes qualitative and quantitative analysis of several respondents who were selected either randomly (purpuse sampling) or based on a commonly used formula. The data obtained from the respondents are based on the results of interviews, both through filling out closed and open questionnaires. In addition to data from interviews, other necessary data are taken from government agencies, the results of previous research by experts, or taken directly at the research location. Based on the results of the study, the potential conflict between the use of sero fishing gear against other fishing gear users only has the potential to use traps, throwing nets, and hand lines. comparison of financing $(\mathrm{R} / \mathrm{C})$, and categorized quickly through analysis of return on investment (PP). The types of sero fishing gear caught consisted of 33 species of fish, 7 species of crustaceans, and 1 species of mollusk. The variety of species caught also proves the level of selectivity of fishing gear sero fishermen in Palopo City is categorized as medium based on species diversity analysis $\left(\mathrm{H}^{\prime}\right)$ and low category based on dominance analysis (D). The results in this study also prove that the level of selectivity of fishing gear sero fishermen in Palopo City is very low even though the level of exploitation of fisheries resources in Palopo City is actually still in the developing stage. Things that can be recommended based on the results of this study are the efficiency of the number of sero fishing gear and the use of mesh sizes as well as increasing efforts to conserve mangroves as a source of primary productivity.
\end{abstract}

Keywords: sero, selectivity, conflict fishermen, fish catch results

\section{Pendahuluan}

Seiring pertumbuhan populasi manusia dan kemajuan teknologi penangkapan menyebabkan tingkat eksploitasi yang semakin meningkat. Pada sisi lain daya dukung lingkungan termasuk sumberdaya ikan mempunyai keterbatasan. Akibat keterbatasan inilah sehingga dibutuhkan adanya pengelolaan pemanfaatan sumberdaya ikan sesuai dengan daya dukung lingkungan. Kegiatan pengelolaan membutuhkan adanya regulasi tentang tingkat pemanfaatan pada setiap wilayah perairan yang akan diproyeksikan menjadi daerah penangkapan ikan. Batasan-batasan perlu ditetapkan sesuai dengan daya dukung lingkungan masingmasing perairan dan bukan hanya terfokus pada seberapa banyak sumberdaya yang didapat. Sero merupakan salah satu dari sekian jenis alat tangkap 
ikan yangseringdioperasikan oleh nelayanpesisir khususnya di wilayah Kota Palopo. Bahan utama yang digunakan dalam pembuatan alat tangkap ini biasanyaterdiri dari bambu atau kayu serta jaring. Kelebihan dari alat tangkap ini adalah dimana pemanenan dapat dilakukan setiap hari dan pengoperasiannya sangatlah mudah serta biaya operasinya relatif murah. Ikan, kepiting, cumi-cumi, lobster, penyu bahkan buaya muara merupakan sebagian kecil contoh variasi jenis biota laut yang dapat terperangkap dalam alat tangkap sero.

Upaya pemanfaatan sumberdaya perikanan tangkap di Kota Palopo dapat ditandai dengan kehadiran berbagai jenis alat tangkap ikan beserta perahu atau kapal yang dijadikan alat transportasi penangkapan. Bagan apung, bagan tancap, pukat dasar, pancing ulur, pancing rawai, purse seine, gill net, bubu dan sero merupakan sederetan contoh jenis alat tangkap tersebut. Khusus mengenai alat tangkap jenis sero, hampir di sepanjang wilayah pesisir Kota Palopo dapat kita temui alat tangkap jenis ini. Ironisnya, hampir di sepanjang wilayah pesisir Kota Palopo sebenarnya merupakan habitat bagi ekosistem mangrove yang merupakan tempat tujuan migrasi bagi hewan-hewan laut untuk melakukan pemijahan (spawning ground), pertumbuhan (nursery ground), dan mencari makan (feeding ground). Selain sangat berpotensi mengancam keberadaan ekositem mangrove termasuk komponen-komponen yang ada di dalamnya, kepadatan dan sebaran alat tangkap ini juga diduga berpotensi mengganggu alur pelayaran bagi nelayan lain khususnya bagi nelayanpengguna alat tangkap yang berbeda (selain sero). Tersedianya data akurat mengenai penggunaan sero serta beberapa aspek penting lainnya yang terdapat di pesisir Kota Palopo akan memberikan kontribusi terhadap pengelolaan sumberdaya pesisir.

\section{Bahan Dan Metode}

\section{Waktu dan Tempat}

Lokasi penelitian ini dilaksanakan di wilayah pesisir Kota Palopo. Waktu penelitian dilaksanakan pada bulan Januari sampai bulan April 2020.

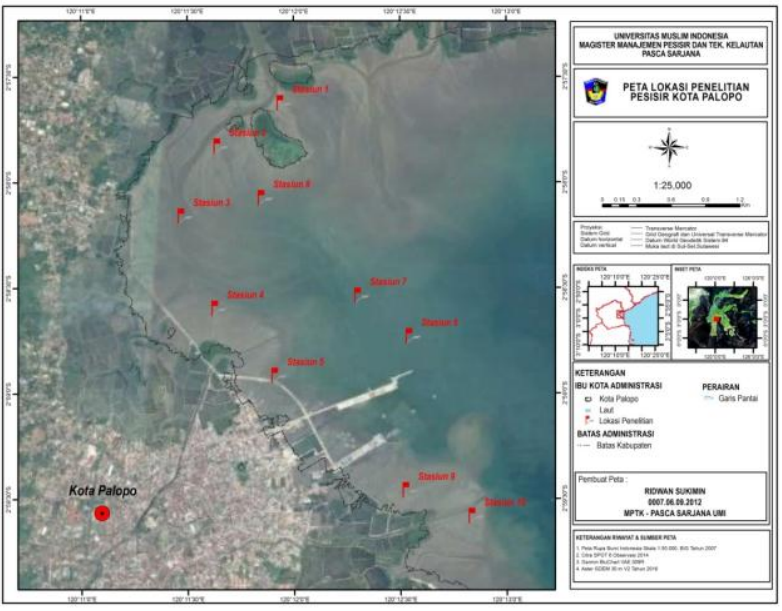

Gambar 1. Lokasi Penelitian

Tabel 1. Bahan-bahan yang digunakan dalam penelitian

\begin{tabular}{|c|l|l|}
\hline No & \multicolumn{1}{|c|}{ Nama } & \multicolumn{1}{|c|}{ Kegunaan } \\
\hline 1 & Ikan hasil tangkapan & Sebagai parameter kajian \\
\hline 2 & Sero & Sebagai objek penelitian \\
\hline 3 & Buku identifikasi & $\begin{array}{l}\text { Mengidentifikasi ikan hasil } \\
\text { tangkapan }\end{array}$ \\
\hline 4 & $\begin{array}{l}\text { Data sekunder jumlah } \\
\text { alat tangkap dan } \\
\text { jumlah } \\
\text { tangkapan }\end{array}$ & Sebagai parameter kajian \\
\hline
\end{tabular}

Tabel 2. Peralatan yang digunakan dalam penelitian

\begin{tabular}{|c|l|c|l|}
\hline No & \multicolumn{1}{|c|}{ Nama } & Jumlah & \multicolumn{1}{|c|}{ Kegunaan } \\
\hline 1 & $\begin{array}{l}\text { Perahu } \\
\text { (katinting) }\end{array}$ & 1 unit & Sarana transportasi \\
\hline 2 & kantong plastik & 10 buah & $\begin{array}{l}\text { Wadahpenampunga } \\
\text { n ikan sementara }\end{array}$ \\
\hline 3 & $\begin{array}{l}\text { Alat tulis } \\
\text { menulis }\end{array}$ & 1 unit & Pencatatan data \\
\hline 4 & Meter & 1 buah & $\begin{array}{l}\text { Mengukur panjang } \\
\text { ikan }\end{array}$ \\
\hline 5 & Kamera & 1 buah & Pendokumentasian \\
\hline
\end{tabular}

\section{Metode Pengumpulan Data}

Data primer adalah data yang dikumpulkan sendiri oleh perorangan atau suatu organisasi secara langsung dari objek yang diteliti dan untuk kepentingan studi. Data primer ini meliputi proses wawancara terhadap responden menyangkut potensi konflik antar nelayan, kontribusi usaha penangkapan serta proses identifikasi variasi jenis dan pengukuran ikan hasil tangkapan sero. Data sekunder diperoleh dari data statistik Dinas Kelautan danPerikanan Kota Palopo. Data tersebut merupakan data time series terkait jumlah alat tangkap sero dan juga alat tangkap selain sero, serta jumlah hasil tangkapan ikan nelayan pesisir Kota Palopo melalui penggunaan alat tangkap sero dalam kurun waktu 6 tahun terakhir. Data sekunder lainnya adalah data yang bersumber dari hasil penelitian para ahli, baik berupa jurnal maupun laporan penelitian yang telah 
dipublikasikan. Data ini diperlukan guna dijadikan acuan dalam menentukan ukuran jenis-jenis ikan tertentu yang telah mengalami fase matang gonad.

\section{Analisis Data}

Tahap pertama pengumpulan data potensi konflik dimulai dari penentuan responden yang akan diwawancarai untuk memperoleh data yang akan dianalisis. Untuk menentukan jumlah responden berdasarkan masing-masing pengguna alat tangkap tersebut digunakan pedoman menurut Slovin (1960) dalam Sevilla et al.. (1993) dalam Rauf (2012):

$$
n=\frac{N}{1+N e^{2}}
$$

Keterangan: $\mathrm{n}=$ Jumlah sampel.

$\mathrm{N}=$ Jumlah populasi.

$\mathrm{e}=$ Error $(0,05)$.

Tahap selanjutnya

adalah mempresentasekan hasil wawancara menggunakan rumus dan tafsiran data dari Arikunto (2002):

Keterangan :

$$
P=\frac{f}{N} x 100
$$

$\mathrm{P}=$ persentase

$\mathrm{f}=$ jumlah responden

$\mathrm{N}=$ jumlah responden seluruhnya

Untuk mempermudah proses analisis, maka dilakukan tafsiran data dengan perincian seperti tersaji pada tabel berikut:

Tabel 3. Tafsiran Data Hasil Wawancara Responden

\begin{tabular}{|c|c|c|}
\hline No & Persentase (\%) & Tafsiran \\
\hline 1 & 0 & Tidak satupun responden \\
\hline 2 & $1-26$ & Sebagian kecil responden \\
\hline 3 & $27-49$ & Hampir setengah responden \\
\hline 4 & 50 & Setengah responden \\
\hline 5 & $51-75$ & Sebagian besar responden \\
\hline 6 & $76-99$ & Hampir seluruh responden \\
\hline 7 & 100 & Seluruh responden \\
\hline
\end{tabular}

Sumber : Arikunto (2002).

Analisis kontribusi usaha melalui perhitungan nilai laba/rugi dilakukan berdasarkan Iskandar dan Guntur (2014) :

Laba $/$ rugi $=$ Total penerimaan -

(Biaya tetap + Biaya variabel).

Kriteria :

$\mathrm{TP}>\mathrm{TBT}+\mathrm{TBV}=$ usaha untung.

$\mathrm{TP}=\mathrm{TBT}+\mathrm{TBV}=$ usaha tidak untung dan tidak rugi.

$\mathrm{TP}<\mathrm{TBT}+\mathrm{TBV}=$ usaha rugi.

Keterangan :

$\mathrm{TP}=$ total penerimaan .

$\mathrm{TBT}=$ total biaya tetap.

$\mathrm{TBV}=$ total biaya variabel .

Rumus dan kriteria penilaian yang digunakan untuk penghitungan $\mathbf{R} / \mathbf{C}$ rasio berdasarkan Iskandar dan Guntur (2014) adalah :

$$
\mathrm{R} / \mathrm{C}=\frac{\text { Total Penerimaan }}{\text { Total biaya tetap }+ \text { Total biaya variabel }}
$$

\section{Kriteria :}

$\mathrm{R} / \mathrm{C}$ rasio $>1$; usaha menguntungkan.

$\mathrm{R} / \mathrm{C}$ rasio $=1$; usaha tidak untung dan tidak rugi.

$\mathrm{R} / \mathrm{C}$ rasio $<1$; usaha rugi.

Rumus yang digunakan untuk penghitungan payback period(PP) berdasarkan Umar (2003) dalam Ningsih et al.. (2013)adalah :

$$
\mathrm{PP}=\frac{\text { Nilai investasi }}{\text { Keuntungan }} \times \text { Periode waktu }
$$

Kriteria penilaian yang digunakan untuk memberikan tafsiran besaran nilai payback period adalah berdasarkan Riyanto (1991) dalam Ningsih et al. . (2013) sebagai berikut :

$\mathrm{PP}<3$ tahun $=$ tingkat pengembalian modal usaha dikategorikan cepat.

PP $3-5$ tahun $=$ tingkat pengembalian modal usaha dikategorikan sedang.

PP $>5$ tahun $=$ tingkat pengembalian modal usaha dikategorikan lambat.

Untuk mengetahui tingkat keanekaragaman spesis hasil tangkapan dilakukan melalui analisis variasi spesis hasil tangkapan berdasarkan indeks keanekaragaman Shannon-Wiener (Odum 1993 dalam Talib 2013) :

$$
H=-\sum_{i=1}^{n}\left(\frac{n i}{N}\right) \ln \left(\frac{n i}{N}\right)
$$

Keterangan :

$\mathrm{H}=$ Indeks keanekaragaman spesis.

$\mathrm{ni}=$ Jumlah spesis ke- $\mathrm{i}$.

$\mathrm{N}=$ Jumlah semua spesis

Nilai keanekaragaman (selektivitas alat tangkap) kemudian ditentukan berdasarkan kriteria menurut Odum (1993) dalam Nurudin (2013) : 
Tabel 4. Kategori Indeks Keanekaragaman

\begin{tabular}{|c|c|c|c|}
\hline No & Keanekaragaman (H') & Kategori & Tingkat selektivitas \\
\hline 1 & $\mathrm{H}^{\prime}<1$ & Rendah & Tinggi \\
\hline 2 & $1<\mathrm{H}^{\prime}<3$ & Sedang & Sedang \\
\hline 3 & $\mathrm{H}^{\prime}>3$ & Tinggi & Rendah \\
\hline
\end{tabular}

Sumber: Odum (1993) dalam Nurudin (2013).

Dominansi individu spesis hasil tangkapan dianalisis berdasarkan Indeks Simpson (Odum 1993dalam Talib 2013) dengan rumus :

Keterangan :
$\mathrm{C}:$ Nilai dominansi.

ni : Jumlah individu spesis ke-i.

$\mathrm{N}$ : Jumlah individu semua spesis.

Nilai dominansi (selektivitas alat tangkap) kemudian ditentukan dengankriteria menurut Odum (1993) dalam Talib (2013):

Tabel 5. Kategori indeks dominansi

\begin{tabular}{|c|c|c|c|}
\hline No & Dominansi $(\mathbf{C})$ & Kategori & Tingkat selektivitas \\
\hline 1 & $0,00<\mathrm{D}<0,50$ & Rendah & Rendah \\
\hline 2 & $0,50<\mathrm{D}<0,75$ & Sedang & Sedang \\
\hline 3 & $0,75<\mathrm{D}<1,00$ & Tinggi & Tinggi \\
\hline
\end{tabular}

Sumber : Odum (1993) dalam Talib (2013).

Untuk mendapatkan nilai atau besaran jumlah ikan layak tangkap dilakukan melalui perbandingan antara ikan hasil tangkapan selama penelitian dengan ikan yang telah mengalami matang gonad dari spesis yang sama yang telah diteliti sebelumnya oleh para ahli (tabel 6). Hasil perbandingan tersebut selanjutnya dibuat dalam bentuk besaran persentase dengan rumus dan tafsiran data berdasarkan Arikunto (2002):

$$
P=\frac{f}{n} \times 100
$$

Keterangan :

$\mathrm{P}=$ persentase .

$\mathrm{f}=$ jumlah spesis layak tangkap.

$\mathrm{n}=$ jumlah seluruh spesis.

Tabel 6. Pustaka pembanding ukuran ikan matang gonad

\begin{tabular}{|c|l|c|l|}
\hline No & \multicolumn{1}{|c|}{ Spesis } & $\begin{array}{c}\text { Ukuran matang } \\
\text { gonad }(\mathbf{c m})\end{array}$ & \multicolumn{1}{|c|}{ Pustaka Acuan } \\
\hline 1 & Alectes indicus & $83,4(11)$ & Kartawij aya, T., dkk. (2011) \\
\hline 2 & Ambassis interruptus & $7.0(\mathrm{SL})$ & Fishbase (2016) \\
\hline 3 & Anguilla mauritiana & $51(11)$ & Krismono dan MRA Putri (2012) \\
\hline 4 & Caranx serfaciatus & $42(\mathrm{SI})$ & Fishbase (2016) \\
\hline 5 & Cephalopholis boenak & $122(\mathrm{SI})$ & Fishbase (2016) \\
\hline 6 & Chanos chanos & $65(11)$ & Fishbase (2016) \\
\hline 7 & Drepane punctaa & $263(\mathrm{U})$ & Kartawij aya, T., dkk. (2011) \\
\hline 8 & Eptnephelus bleekeri & $36(11)$ & Fishbase (2016) \\
\hline 9 & Gerres filamentosus & $9(11)$ & Aram i, H. dan A Mustafa (2010) \\
\hline 10 & Letognaihus equulus & $8: 5(\mathrm{~T} 1)$ & Pertiwi, W. (2011) \\
\hline 11 & Lutjanus argentimaculatus & $50(\mathrm{FL})$ & Russel, D.J. dan A J. NfcDougall (2008) \\
\hline 12 & Lutjanus russellu & $29(11)$ & Fishbase (2016) \\
\hline 13 & iuraenesax bagio & $47(11)$ & Elst (1981) dalam Guastella (2016) \\
\hline 14 & Oreochromis mossambicus & $15,4(11)$ & Fishbase (2016) \\
\hline 15 & Parastromateus niger & $23.8(\mathrm{Fl})$ & Rachma, H., (2015) \\
& & & \\
\hline
\end{tabular}


Sukimin et al. (2021). Jurnal Biologi Tropis, 21 (2): 564 - 575

DOI: http://dx.doi.org/10.29303/jbt.v21i2.2743

\begin{tabular}{|c|l|c|l|}
\hline 16 & Pseudorhombus elevatus & $23,7(\mathrm{U})$ & Hadiemi, S.A, \&k. (2013) \\
\hline 17 & P.astrelliger brachysoma & $18(\mathrm{~K})$ & Larasati,D.A (2011) \\
\hline 18 & Sardinella ftmbriata & $13.8(\mathrm{U})$ & Fishbase $(2016)$ \\
\hline 19 & Scatophagus argus & $14(\mathrm{U})$ & Fishbase $(2016)$ \\
\hline 20 & Scomberoides tala & $47,5(\mathrm{Fl})$ & Griffiths, S., $d<k .(2005)$ \\
\hline 21 & Scomberomorus lineolatus & $70(\mathrm{U})$ & Fishbase $(2016)$ \\
\hline 22 & Siganus guttatus & $26(\mathrm{U})$ & Widiana $(2015)$ \\
\hline 23 & Siganus vermiculatus & $26.8(\mathrm{U})$ & Tuegeh, S., dkc. $(2012)$ \\
\hline 24 & Sillago sihama & $16(11)$ & Fishbase $(2016)$ \\
\hline 25 & Terapon jarbua & $13(\mathrm{SI})$ & Fishbase $(2016)$ \\
\hline 26 & Trichiurus lepturus & $39(\mathrm{U})$ & Fishbase $(2016)$ \\
\hline 27 & Ty los urus strongy lurus & $75(\mathrm{Fl})$ & Tamarol, $d<k .(2012)$ \\
\hline 28 & Upeneus sulphureuz & $9,9(\mathrm{Fl})$ & Fishbase $(2016)$ \\
\hline 29 & Valamugil buchanani & $36(\mathrm{SI})$ & Fishbase $(2016)$ \\
\hline
\end{tabular}

Keterangan: $T L$ - total length $F L=$ fork length $S L=$ standar length Sumber:

Data sekunder 2016

Untuk mempermudah proses analisis, maka dilakukan tafsiran data berdasarkan tafsiran data seperti yang tersaji pada tabel berikut:

Tabel 7. Tafsiran data ikan layak tangkap

\begin{tabular}{|c|c|c|}
\hline No & Persentase (\%) & Tingkat selektivitas \\
\hline 1 & $0-20$ & Sangat rendah \\
\hline 2 & $21-40$ & Rendah \\
\hline 3 & $41-60$ & Sedang \\
\hline 4 & $61-80$ & Tinggi \\
\hline 5 & $81-100$ & Sangat tinggi \\
\hline
\end{tabular}

Sumber : Arikunto (2002).

Analisis tingkat pemanfaatan ditentukan berdasarkan nilai cath per unit effort (CPUE). Rumus yang digunakan adalah untuk mengetahui nilai CPUE adalah berdasarkan Sparre dan Venema (1999)dalam Raspati (2008) :

$$
\text { CPUE }=\frac{\text { Cath }}{\text { Effort }}
$$

\section{Hasil dan Pembahasan}

\section{a. Potensi Konflik Antar Nelayan Tangkap}

Berdasarkan hasil wawancara tentang potensi gangguan akan keberadaan alat tangkap sero terhadap responden pengguna alat tangkap bubu, jala lempar, pancing ulur, bagan apung, bagan tancap, pancing rawai, purse seine serta gill net, menunjukan adanya variasi jawaban (Tabel 8)

Tabel 8. Hasil rekapitulasi jawaban responden

\begin{tabular}{|c|c|c|c|c|c|c|}
\hline \multirow{2}{*}{ No } & \multirow{2}{*}{$\begin{array}{c}\text { Nama alat } \\
\text { tangkap }\end{array}$} & \multirow{2}{*}{$\begin{array}{c}\text { Jumlah } \\
\text { responden }\end{array}$} & \multicolumn{4}{|c|}{ Jawaban responden } \\
\cline { 4 - 7 } & & & Jumlah & $\%$ & Jumlah & \%enganggu \\
\hline 1 & Bagan apung & 23 & 0 & 0 & 23 & 100 \\
\hline 2 & Bagan tancap & 24 & 0 & 0 & 24 & 100 \\
\hline 3 & Bubu & 94 & 57 & 60,64 & 37 & 39,36 \\
\hline 4 & Jala lempar & 50 & 50 & 100 & 0 & 0 \\
\hline 5 & Pancing rawai & 14 & 0 & 0 & 14 & 100 \\
\hline 6 & Pancing ulur & 35 & 34 & 97,15 & 1 & 2,85 \\
\hline 7 & Purse seine & 19 & 0 & 0 & 19 & 100 \\
\hline 8 & Gill net & 65 & 0 & 0 & 65 & 100 \\
\hline
\end{tabular}

Sumber : Data primer 2016. 
Apabila dicermati berdasarkan variasi jawaban yang dikaitkan dengan lokasi atau wilayah operasi alat tangkap, maka responden kedelapan pengguna alat tangkap tersebut dapat dibagi dalam 2 kelompok besar. Kelompok pertama terdiri dari responden pengguna alat tangkap bagan apung, bagan tancap, pancing rawai, purse seine serta gill net, yang kesemua $(100 \%)$ responden menyatakan bahwa keberadaan alat tangkap sero tidak mengganggu aktivitas kenelayanan mereka khususnya berkaitan dengan alur pelayaran. Berdasarkan lokasi operasi alat tangkap bagan apung, bagan tancap, pancing rawai, purse seine, serta gill net, berada pada zona neritik atau wilayah yang selalu mengalami penggenangan air laut sepanjang tahun, bahkan jauh sampai ke wilayah lautan. Lokasi ini tentunya berbeda dengan lokasi umumnya alat tangkap sero dioperasikan. Lokasi pengoperasian alat tangkap sero umumnya berada pada zona pasang surut (litoral) yang seringkali mengalami kekeringan dan penggenangan air laut secara berkala. Selain karena adanya perbedaan wilayah operasi, Pemerintah Kota Palopo telah mengantisipasi potensi konflik tersebut melalui penyediaan jalur khusus bagikapal-kapal atau perahu nelayan dari lokasi tambatan menuju ke arah lautan, ataupun sebaliknya. Jalur tersebut kemudian dimanfaatkan oleh pengguna alat tangkapbagan apung, bagan tancap, pancing rawai, purse seine, serta gill net untuk kegiatan kenelayanannya.

Kelompok kedua terdiri atas responden pengguna alat tangkap bubu, pancing ulur, serta jala. Berdasarkan hasil wawancara menunjukan adanya gangguan yang dirasakan responden akan keberadaan alat tangkap sero, walaupun besaran persentase gangguan tersebut bervariasi. Wilayah operasi alat-alat tangkap ini sangat berdekatan dengan tempat terpasangnya alat tangkap sero. Adanya kesamaan lokasi penangkapan tersebut sangat memungkinkan untuk terjadinya konflik walaupun besaran konflik tersebut seperti yang telah disebutkan sebelumnya adalah bervariasi dan diduga berkaitan dengan luasan areal operasi penangkapan dan sifat atau karakteristik operasi penangkapan. Semakin luas areal operasi penangkapan dan semakin tinggi durasi penangkapan akan semakin berpotensi terjadinya konflik.

\section{b. Kontribusi Usaha Penggunaan Alat Tangkap Sero}

Berdasarkan hasil analisis data dari sepuluh unit alat tangkap sero yang menjadi stasiun penelitian, diperoleh kisaran laba antara Rp.191.828 - Rp.817.127. Jika dirata-ratakan kisaran laba dari kesepuluh stasiun penelitian tersebut, maka terlihat gambaran pendapatan nelayan pengguna alat tangkap sero Kota Palopo dalam 1 unit adalah sebesar Rp.443.474 per bulan. Hasil analisis laba/rugi yang menunjukan adanya laba usaha dapat diartikan bahwa usaha penangkapan ikan melalui penggunana alat tangkap sero menguntungkan. Gittinger(1986) dalamAmrizal (2011) menyatakan bahwa kelayakan dari suatu kegiatan usaha diperhitungkan atas dasar besarnya laba finansial yang diharapkan. Kegiatan usaha dikatakan layak jika memberikan keuntungan finansial, sebaliknya kegiatan usaha dikatakan tidak layak apabila usaha tersebut tidak memberikan keuntungan finansial.

Hasil analisis $\mathrm{R} / \mathrm{C}$ rasio tertinggi terdapat pada stasiun 4 sebesar 2,6 dan yang terendah terdapat pada stasiun 6 sebesar 1,3. Jika nilai R/C rasio pada kesepuluh stasiun penelitian tersebut dirata-ratakan maka didapat nilai sebesar 1,9. Besaran nilai ini dapat diartikan bahwa setiap 1,0 rupiah biaya yang dikeluarkan dalam usaha penangkapan ikan oleh nelayan pengguna alat tangkap sero akan menghasilkan keuntungan sebesar 1,9 rupiah. Besaran rata-rata nilai penerimaan $\mathrm{R} / \mathrm{C}$ yang lebih besar dari nilai 1,0 menunjukan usaha penangkapan ikan oleh nelayan melalui penggunan alat tangkap sero di Kota Palopo dapat dikatakan menguntungkan. Hernanto (1989) dalam Afriyanto (2008) menyatakan bahwa analisis R/Crasiobertujuan untuk melihat seberapa jauh setiap nilai rupiah dari biaya yang digunakan dalam kegiatan usaha perikanan dapat memberikan sejumlah nilai penerimaan sebagai manfaatnya. Kegiatan usaha yang paling menguntungkan mempunyai R/Crasiopaling besar.

Hasil analisis payback period dari yang tertinggi terdapat pada stasiun 6 sebesar 6 tahun 0 bulan dan yang terendah terdapat pada stasiun 4 sebesar 1 tahun 0 bulan. Jika hasil analisis payback period tersebutdirata-ratakan, akan didapat nilai sebesar 2,6. Besaran nilai ini dapat menjadi sebuah gambaran berkaitan denganrata-rata waktu yang dibutuhkan oleh nelayan pengguna alat tangkap sero di Kota Palopo dalam mengembalikan biaya investasi yaitu 2 tahun 6 bulan. Berdasarkan kriteria penilaian yang digunakan, maka tingkat pengembalian modal usaha perikanan tangkap melalui penggunaan alat tangkap sero di pesisir Kota Palopo dapat dikategorikan cepat. Semakin rendah nilai payback period, maka akan semakin baik usaha tersebut. Begitupula sebaliknya, semakin tinggi nilai payback period usaha tersebut, maka dapat dikatakan semakin buruk usaha itu. Pada umumnya kriteria penilaian analisis payback period (PP) tidak menekankan pada layak atau tidak layak suatu usaha, akan tetapi lebih menekankan pada penilaian kecepatan pengembalian biaya investasi. Husnan dan Suwarsono (2000)dalam Mananda (2011) 
menyatakan bahwa analisispayback period merupakan suatu analisis yang mencoba mengukur seberapa cepat suatu investasi bisa kembali. Karena itulah satuan hasilnya bukan persentase, tetapi satuan waktu seperti tahun dan bulan. c. Selektivitas Alat Tangkap Sero

Spesis yang berhasil ditemukan dan diidentifikasi (hasil tangkapan) selama penelitian terdiri 33 spesis ikan, 7 spesis krustasea, dan 1 spesis moluska. Total hasil tangkapan secara keseluruhan adalah 41 spesis dan 23777 individu (tabel 9).

Tabel 9. Jumlah spesis hasil tangkapan selama penelitian

\begin{tabular}{|c|c|c|c|c|c|c|c|c|c|c|c|c|}
\hline \multirow{2}{*}{ No } & \multirow{2}{*}{ Spesies tangkapan } & \multicolumn{10}{|c|}{ Stasiun } & \multirow{2}{*}{ Jmlh } \\
\hline & & 1 & 2 & 3 & 4 & 5 & 6 & 7 & 8 & 9 & 10 & \\
\hline 1 & Acentrogobius sp. & 42 & 28 & 16 & 13 & 11 & 8 & 31 & 6 & 104 & 18 & 277 \\
\hline 2 & $\begin{array}{l}\text { Alectes indicus } \\
\text { Ambassis }\end{array}$ & 17 & 6 & - & - & - & - & 53 & - & - & 10 & 86 \\
\hline 3 & $\begin{array}{l}\text { interruptus } \\
\text { Anguilla }\end{array}$ & 110 & 174 & 1165 & 1235 & 635 & 720 & 538 & 1630 & 920 & 425 & 7552 \\
\hline 4 & mauritiana & 3 & - & - & - & - & - & 1 & 1 & 2 & 2 & 9 \\
\hline 5 & $\begin{array}{l}\text { Caranx sexfaciatus } \\
\text { Cephalopholis }\end{array}$ & - & - & - & - & 43 & 32 & 6 & 15 & - & - & 96 \\
\hline 6 & boenak & - & - & 3 & - & 2 & - & - & - & - & - & 5 \\
\hline 7 & Chanos chanos & - & 2 & 2 & 3 & 1 & - & - & - & - & 3 & 11 \\
\hline 8 & $\begin{array}{l}\text { Drephane punctata } \\
\text { Epinephelus }\end{array}$ & - & - & 2 & - & - & - & - & - & - & - & 2 \\
\hline 9 & bleekeri & - & 2 & - & - & - & - & - & 1 & 16 & 1 & 20 \\
\hline 10 & $\begin{array}{l}\text { Gerres filamentosus } \\
\text { Leioghnatus }\end{array}$ & 6 & 3 & 38 & 11 & 33 & - & 19 & 7 & 47 & 128 & 292 \\
\hline 11 & $\begin{array}{l}\text { equulus } \\
\text { Lutjanus }\end{array}$ & 510 & 85 & 3170 & 1162 & 255 & 1961 & 630 & 1320 & 1327 & 330 & 10750 \\
\hline 12 & argentimaculatus & - & - & - & 1 & - & - & - & - & - & - & 1 \\
\hline 13 & Loligo sp. & - & - & - & & - & - & - & - & - & 2 & 2 \\
\hline 14 & Lutjanus rusellii & 14 & 25 & 14 & 8 & 27 & 10 & 5 & - & 9 & 6 & 118 \\
\hline 15 & Metapenaeus sp. & 125 & 45 & 37 & 230 & 24 & 26 & 33 & 48 & 165 & 97 & 830 \\
\hline 16 & Metaplax elegans & 5 & 7 & 17 & 12 & 9 & 6 & 27 & 12 & 11 & 14 & 120 \\
\hline 17 & Muraenesox bagio & - & 2 & 1 & - & - & - & - & 1 & - & - & 4 \\
\hline 18 & $\begin{array}{l}\text { Oratosquilla nepa } \\
\text { Oreochromis }\end{array}$ & 5 & 5 & 7 & 2 & - & - & 13 & 11 & 3 & 8 & 54 \\
\hline 19 & $\begin{array}{l}\text { mossambicus } \\
\text { Parastromateus }\end{array}$ & - & - & 2 & - & - & - & - & - & 1 & 3 & 6 \\
\hline 20 & $\begin{array}{l}\text { niger } \\
\text { Penaeus }\end{array}$ & 2 & - & - & - & - & 2 & - & - & - & - & 4 \\
\hline 21 & merguiensis & 95 & 245 & 445 & 63 & 110 & 73 & 158 & 82 & 284 & 122 & 1677 \\
\hline 22 & Penaeus monodon & - & - & - & 3 & - & - & - & 1 & & 2 & 6 \\
\hline 23 & $\begin{array}{l}\text { Portunus sp. } \\
\text { Pseudorhombus }\end{array}$ & 4 & - & 3 & 6 & - & - & 1 & - & 2 & 3 & 19 \\
\hline 24 & $\begin{array}{l}\text { elevatus } \\
\text { Rastrelliger }\end{array}$ & - & - & - & 3 & - & - & 2 & 8 & - & - & 13 \\
\hline 25 & $\begin{array}{l}\text { brachysoma } \\
\text { Sardinella }\end{array}$ & - & 21 & 71 & - & - & 19 & 29 & 114 & 14 & - & 268 \\
\hline 26 & fimbriata & - & 7 & & - & - & 32 & 15 & 38 & 7 & - & 99 \\
\hline 27 & Scatophagus argus & 9 & - & 7 & 6 & 2 & - & - & - & 5 & 4 & 33 \\
\hline 28 & $\begin{array}{l}\text { Scomberoides tala } \\
\text { Scomberomorus }\end{array}$ & - & 6 & & 4 & - & - & 28 & 78 & 5 & 56 & 177 \\
\hline 29 & lineolatus & - & - & 1 & 1 & - & - & & - & - & - & 2 \\
\hline
\end{tabular}




\begin{tabular}{|c|c|c|c|c|c|c|c|c|c|c|c|c|}
\hline 30 & Scylla serrata & 2 & 2 & 2 & 5 & 1 & 2 & 6 & 1 & 1 & 4 & 26 \\
\hline 31 & $\begin{array}{l}\text { Siganus guttatus } \\
\text { Siganus }\end{array}$ & - & 3 & 2 & - & - & - & - & - & - & - & 5 \\
\hline 32 & vermiculatus & - & - & - & - & 2 & 3 & 4 & 2 & 2 & 9 & 22 \\
\hline 33 & $\begin{array}{l}\text { Sillago sihama } \\
\text { Taenioides }\end{array}$ & 3 & - & 8 & 11 & 1 & 8 & 10 & - & 25 & 14 & 80 \\
\hline 34 & anguillaris & 17 & 4 & 16 & 3 & 15 & 14 & 15 & 7 & 8 & 13 & 112 \\
\hline 35 & Terapon jarbua & - & - & 3 & 64 & - & 12 & 109 & 89 & 40 & 24 & 341 \\
\hline 36 & Tetraodon hispidus & 6 & - & 10 & 4 & 7 & 11 & 2 & 10 & 15 & 16 & 81 \\
\hline 37 & Toxotes jaculatrix & - & 3 & 8 & - & 3 & - & - & - & 2 & 11 & 27 \\
\hline 38 & $\begin{array}{l}\text { Trichiurus lepturus } \\
\text { Tylosurus }\end{array}$ & - & - & - & - & - & 2 & - & 3 & 7 & - & 12 \\
\hline 39 & $\begin{array}{l}\text { strongylurus } \\
\text { Upeneus }\end{array}$ & 2 & 25 & 11 & 5 & - & 1 & 2 & 1 & 38 & 38 & 123 \\
\hline 40 & $\begin{array}{l}\text { sulphureus } \\
\text { Valamugil }\end{array}$ & 4 & - & 19 & 63 & - & - & 78 & 184 & 20 & 23 & 391 \\
\hline \multirow[t]{3}{*}{41} & buchanani & 7 & 4 & - & 5 & 5 & - & - & - & - & 3 & 24 \\
\hline & Total individu & 988 & 704 & 5080 & 2923 & 1186 & 2942 & 1815 & 3670 & 3080 & 1389 & 23777 \\
\hline & Total spesies & 21 & 22 & 27 & 25 & 19 & 19 & 25 & 25 & 27 & 29 & 41 \\
\hline
\end{tabular}

Sebaran nilai indeks keanekaragaman $\left(\mathrm{H}^{\prime}\right)$ berkisar dari yang tertinggi terdapat pada stasiun 10 dengan nilai $\mathrm{H}^{\prime}=2,21$, dan yang terendah terdapat stasiun 6 dengan nilai $H^{\prime}=1,03$. Melalui sebaran nilai $H^{\prime}$ tersebut dapat diartikan pula bahwa tingkat selektivitas alat tangkap tertinggi terdapat pada stasiun 6 dan yang terendah terdapat pada stasiun 10 . Berdasarkan hasil analisis data indeks keanekaragaman menunjukan bahwa keanekaragaman spesis hasil tangkapan melalui penggunaan alat tangkap sero nelayan pesisir Kota Palopo untuk semua stasiun penelitian masuk dalam kategori ukuran sedang. Variasi spesis maupun jumlah individu hasil tangkapan sero bukan hanya dipengaruhi oleh ketersediaan sumberdaya di wilayah tersebut, akan tetapi juga dipengaruhi oleh bermacam-macam faktor seperti : musim penangkapan, posisi pemasangan alat tangkap, sertakualitas alat tangkap.

Berdasarkan hasil analisis nilai dominansi, nilai tertinggi terdapat pada stasiun 6 dengan nilai $\mathrm{D}$ $=0,50$ dan yang terendah terdapat pada stasiun 10 dengan nilai $\mathrm{D}=0,17$. Besaran kisaran dominansi ini menunjukan bahwa kriteria dominansi spesis untuk semua stasiun penelitian dikategorikan rendah. Rendahnya nilai dominansi dapat diartikan juga bahwa selektivitas alat tangkap sero yang digunakan nelayan pesisir Kota Palopo adalah rendah. Menurut Odum (1993) dalam Talib (2013) bahwa nilai dominansi (D) tinggi jika $0,75<\mathrm{D}<$ 1,00 , sedang jika $0,50<\mathrm{D}<0,75$, dan rendah jika $0,00<\mathrm{D}<0,50$. Semakin tinggi nilai dominansi mengindikasikan tingkat selektivitas alat tangkap juga semakin tinggi. Begitupula semakin rendah nilai dominansi mengindikasikan semakin rendah pula tingkat selektivitas alat tangkap.

Berdasarkan hasil identifikasi terhadap spesis ikan hasil tangkapan selama penelitian, terdapat 29 spesis ikan hasil tangkapan yang dapat dikelompokan sebagai hasil tangkapan utama (primary catch) dan hasil tangkapan sampingan (by catch). Dari ke 29 spesis tersebut, 10 spesis diantaranya merupakan hasil tangkapan utama dan 19 spesis merupakan hasil tangkapan sampingan yang masih bernilai secara ekonomis (tabel 10). Hasil analisis pada penelitian ini juga menunjukan bahwa stasiun yang memiliki persentase jumlah ikan layak tangkap tertinggi atau jumlah ikan tidak layak tangkap terendah terdapat pada stasiun $2(19,5 \%$ layak dan $80,5 \%$ tidak layak), sedangkan stasiun yang memiliki persentase jumlah ikan layak tangkap terendah atau jumlah ikan tidak layak tangkap tertinggi terdapat pada stasiun $6(2,1 \%$ layak dan $97,9 \%$ tidak layak).

Salah satu faktor yang sangat menentukan tingkat selektivitas alat tangkap perikanan adalah penggunaan ukuran mata jaring (mesh size). Menentukan pilihan terhadap ukuran mata jaring memerlukan perhitungan yang tepat dan hal ini sepertinya masih menjadi satu kendala khususnya bagi nelayan pengguna alat tangkap sero yang ada di Kota Palopo. Menentukan pilihan yang tepat terhadap ukuran mata jaring dapat diartikan sebagai suatu upaya dalam memaksimalkan potensi sumberdaya perikanan guna peningkatan taraf hidup nelayan dengan tetap mempertimbangkan aspek 
ketersedian sumberdaya perikanan atau

keberlanjutan usaha penangkapan itu sendiri.

Tabel 10. Kelompok ikan Hasil tangkapan dan kategori layak tangkap

\begin{tabular}{|c|c|c|c|c|c|c|c|}
\hline \multirow{3}{*}{ No } & \multirow{3}{*}{ Spesis } & \multirow{3}{*}{ Kelompok } & \multirow{3}{*}{$\begin{array}{c}\text { Jumlah } \\
\text { tangkapan }\end{array}$} & \multicolumn{4}{|c|}{ Hasil tangkapan } \\
\hline & & & & \multicolumn{2}{|c|}{ Layak } & \multicolumn{2}{|c|}{ Tidak layak } \\
\hline & & & & Jumlah & $\%$ & Jumlah & $\%$ \\
\hline 1 & A. indicus & HTU & 86 & 0 & 0 & 86 & 100 \\
\hline 2 & A. interruptus & HTS & 7552 & 846 & 11,2 & 6706 & 88,8 \\
\hline 3 & A. mauritiana & HTS & 9 & 9 & 100 & 0 & 0 \\
\hline 4 & C. sexfaciatus & HTU & 96 & 0 & 0 & 96 & 100 \\
\hline 5 & C. boenak & HTU & 5 & 3 & 60 & 2 & 40 \\
\hline 6 & C. chanos & HTS & 11 & 1 & 9,1 & 10 & 90,9 \\
\hline 7 & D. punctata & HTS & 2 & 0 & 0 & 2 & 100 \\
\hline 8 & E. bleekeri & HTU & 20 & 0 & 0 & 20 & 100 \\
\hline 9 & G. filamentosus & HTS & 292 & 23 & 7,9 & 269 & 92,1 \\
\hline 10 & L. equulus & HTS & 10750 & 572 & 5,3 & 10178 & 94,7 \\
\hline 11 & L. argentimaculatus & HTU & 1 & 0 & 0 & 1 & 100 \\
\hline 12 & L. russellii & HTS & 118 & 0 & 0 & 118 & 100 \\
\hline 13 & M. bagio & HTS & 4 & 4 & 100 & 0 & 0 \\
\hline 14 & O. mossambicus & HTU & 6 & 6 & 100 & 0 & 0 \\
\hline 15 & P. niger & HTS & 4 & 0 & 0 & 4 & 100 \\
\hline 16 & P. elevatus & HTS & 13 & 1 & 7,7 & 12 & 92,3 \\
\hline 17 & R. brachysoma & HTS & 268 & 9 & 3,4 & 259 & 96,6 \\
\hline 18 & S. fimbriata & HTS & 99 & 4 & 4 & 95 & 96 \\
\hline 19 & S. argus & HTU & 33 & 2 & 6,1 & 31 & 93,9 \\
\hline 20 & S. tala & HTS & 177 & 0 & 0 & 177 & 100 \\
\hline 21 & S. lineolatus & HTU & 2 & 0 & 0 & 2 & 100 \\
\hline 22 & S. guttatus & HTU & 5 & 1 & 20 & 4 & 80 \\
\hline 23 & S. vermiculatus & HTU & 22 & 1 & 4,5 & 21 & 95,5 \\
\hline 24 & S. sihama & HTS & 80 & 35 & 43,8 & 45 & 56,2 \\
\hline 25 & T. jarbua & HTS & 341 & 7 & 2,1 & 334 & 97,9 \\
\hline 26 & T. lepturus & HTS & 12 & 0 & 0 & 12 & 100 \\
\hline 27 & T. strongylurus & HTS & 123 & 0 & 0 & 123 & 100 \\
\hline 28 & U. sulphureus & HTS & 391 & 63 & 16,1 & 328 & 83,9 \\
\hline 29 & V. buchanani & HTS & 24 & 0 & 0 & 24 & 100 \\
\hline
\end{tabular}

Keterangan: $H T U=$ hasil tangkapan utama, $H T S=$ hasil tangkapan sampingan.

Sumber: Data primer 2016.

\section{d. Catch Per Unit effort}

Hasil analisis produksi alat tangkap sero nelayan pesisir Kota Palopo nampak mengalami kenaikan setiap tahunnya $(2010$ - 2015). Kuat dugaan akan kenaikan jumlah produksi yang terjadi pada setiap tahun ini berhubungan dengan menurunnya jumlah alat tangkap sero yang tejadi hampir setiap tahun. Nelwan et al.. (2013) menyatakan bahwa laju produksi dalam kegiatan perikanan tangkap ditentukan oleh seberapa besar upaya penangkapan yang memapar suata daerah 
penangkapan ikan. Ketika sejumlah upaya penangkapan mengeksploitasi lebih rendah dibandingkan stok ikan yang tersedia, maka stok ikan yang tersisa masih dapat tumbuh dan berkembang. Dengan demikian produksi ikan akan meningkat proporsional terhadap upaya penangkapan.

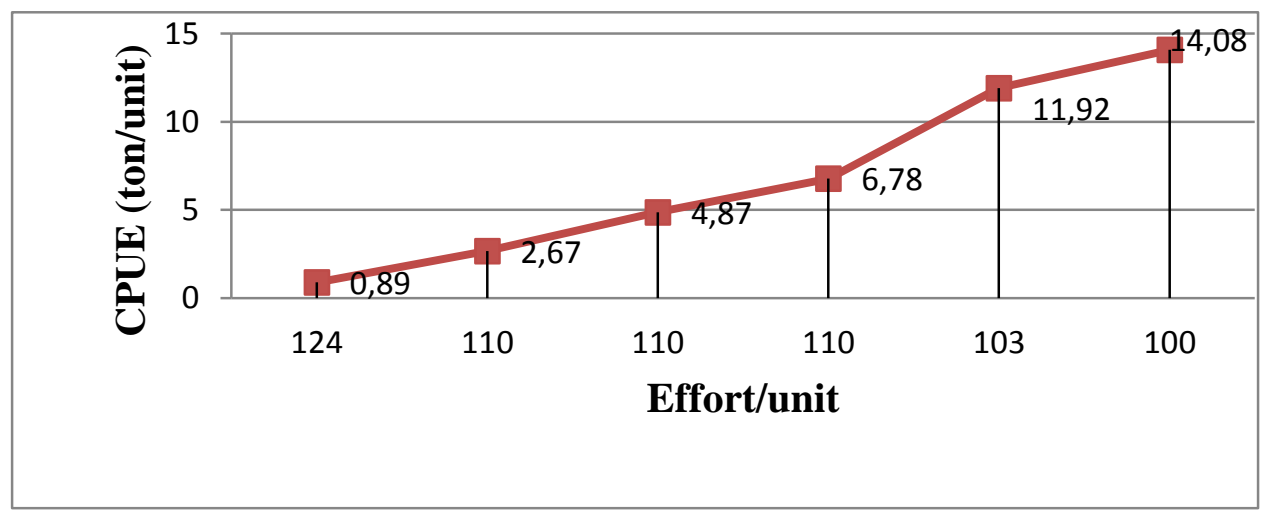

Gambar 2. Nilai CPUE Penggunaan alat tangkap sero.

Analisis hasil tangkapan per upaya penangkapan (CPUE) menunjukan bahwa tingkat eksploitasi sumberdaya perikanan oleh nelayan pengguna alat tangkap sero di pesisir Kota Palopo dapat dikatakan masih pada tahapan berkembang. Kondisi seperti ini mengindikasikan masih terbukanya peluang bagi pengembangan alat tangkap sero atau setidaknya kondisi seperti ini dapat dipertahankan agar sumberdaya yang ada masih dapat terus memberikan kontribusi bagi pendapatan masyarakat, khususnya bagi nelayan pengguna alat tangkap sero. Cahyani (2013) menyatakan bahwa laju eksploitasi sumberdaya ikan yang tinggi dan melebihi daya dukungnya berdampak langsung terhadap keberlanjutan ketersediaan sumberdaya, mempercepat proses kerusakan sumberdaya ikan dan untuk jangka panjang dapat menurunkan pertumbuhan ekonomi. Oleh karena itu, sumberdaya perikanan perlu dikelola secara lestari dengan memperhatikan kaidah pengelolaan yang mendukung kesinambungan ketersediaan sumberdaya.

\section{Kesimpulan}

Berdasarkan fungsi pemanfaatan laut sebagai alur transportasi di pesisir Kota Palopo, penggunaan alat tangkap ikan jenis sero berpotensi konflik terhadap pengguna alat tangkap ikan jenis bubu, jala, dan pancing ulur, namun tidak berpotensi konflik terhadap pengguna alat tangkap ikan jenis bagan apung, bagan tancap, pancing rawai, purse seine, dan gill net. Berdasarkan aspek finansial laba/rugi, penggunaan alat tangkap sero oleh nelayan pesisir di Kota Palopo dinilai layak karena dapat menghasilkan laba rata-rata sebesar Rp.443.474.- dalam 1 unit/bulan. Keuntungan relatif penggunaan alat tangkap sero terhadap biaya yang dikeluarkan (R/C) dinilai juga menguntungkan, dimana dalam 1 rupiah biaya yang dikeluarkan akan menghasilkan keuntungan rata-rata sebesar 1,9 rupiah. Pengembalian modal investasi (PP) usaha membutuhkan waktu rata-rata 2 tahun 6 bulan, sehingga dapat dikategorikan sedang. Spesis hasil tangkapan sero nelayan pesisir Kota Palopo sebanyak 41 spesis yang terdiri dari 33 spesis ikan, 7 spesis krustasea, dan 1 spesis moluska. Alat tangkap ikan jenis sero nelayan pesisir Kota Palopo memiliki tingkat selektivitas variasi jenis dengan kategori sedang terhadap keanekaragaman spesis tangkapan dan berkategori rendah untuk dominansi spesis. Berdasarkan ukuran hasil tangkapan, alat tangkap sero tersebut memiliki tingkat selektivitas yang sangat rendah atau sangat tidak selektiv terhadap ukuran spesis tangkapan. Tingkat eksploitasi sumberdaya perikanan oleh nelayan pengguna alat tangkap sero di pesisir Kota Palopo masih pada tahapan berkembang. Hal ini ditandai dengan cenderung menurunya upaya penangkapan sejak tahun 2010 hingga tahun 2015, serta cenderung meningkatnya produksi usaha penangkapan.

\section{Referensi}

Afriyanto, D. (2008). Analisis Finansial Unit Penangkapan Payang di desa Padelegan, Kecamatan Pademawu, Kabupaten Pamekasan, Provinsi Jawa Timur. Bogor: Fakultas Perikanan dan Ilmu Kelautan IPB.

Amrizal (2011). Analisis Finansial Usaha Peternakan Ayam Broiler Di peternakan 
Karisa Kelurahan Simpang Baru Kecamatan Tampan Kota Pekanbaru. Riau: Fakultas Pertanian Dan Peternakan. Universitas Islam Negeri Sultan Syarif Kasim Riau.

Arami, H., \& Mustafa, A. (2010). Analisis Selektivitas Gill net Yang Dioperasikan Di Perairan Lentea, Kecamatan Kaledupa Selatan Kabupaten Wakatobi. Warta Wiptek , https://adoc.pub/analisis-selektivitas-gillnetyang-dioperasikan-di-perairan-.html.

Arikunto, S. (2002). Prosedur Suatu Penelitian: Pendekatan Praktek. Jakarta: Penerbit Rineka Cipta. Jakarta.

Cahyani, R. T. (2013). Kajian Penggunaan Cantrang Terhadap Kelestarian Sumberdaya Ikan Demersal (Analisis Hasil Tangkapan Dominan Yang Di Daratkan DI TPI Wedung Demak). Semarang.: Program Magister Ilmu Lingkungan, Program Pascasarjana, Universitas Diponegoro.

Froese, R., \& D, P. (2016, Oktober 10). https://www.fishbase.de/. Retrieved April 14, 2020, from https://www.catalogueoflife.org/data/dataset/ 1010:

https://www.catalogueoflife.org/data/dataset/ $\underline{1010}$

Griffiths, S., Fry, G., \& Velde, T. V. (2005). Age, Growth Reproductive Dynamics Of Talang Queenfish (Scomberoides commersonnianus) In Northern Australia. Australia: Australian Government. Department Of The Environment Heritage.

Guastella, L. A. (2010). A Quantitative Assessment Of Recreational Angling In Durban HarbourSouth Africa. South African Journal of Marine science http://dx.doi.org/10.2989/0257761947842871 $\underline{20}$.

Hashemi, S. A., Taghavimotlagh, S. A., Hedayati, A., \& Ghorbani, R. (2013). Spawning Cycle, GSI Index And Length Maturity Of Deep Flounder In Northeast Of Persian Gulf, Iran. Journal Of Animal And Poultry Science. , http://www.japsc.com/wpcontent/uploads/2013/02/Hashemi-JAPSC2013-2-1-1-10.pdf.

Iskandar, D., \& Guntur, A. (2014). Efisiensi Teknis Dan Ekonomi Alat Tangkap Garuk dan
Peluang Pengembangannya Di Desa Rawameneng, Kabupaten Subang. Maspari Journal https://doi.org/10.36706/maspari.v6i2.1816.

Kartawijaya, T., Ardani, A., Hamka, E., Komarudin, D., Jati, A. K., Thenu, I. M., et al. (2011). Analisis Tingkat Keramahan Lingkungan Alat Tangkap Trammel Net Di Teluk Pelabuhan Ratu. Buletin PSP https://journal.ipb.ac.id/index.php/bulpsp/arti cle/view/4149.

Krismono, K., \& Anwar Putri, M. R. (2012). Analisis Tingkat Keramahan Lingkungan Alat Tangkap Trammel Net Di Teluk Pelabuhan Ratu. Jurnal Penelitian Perikanan Indonesia, http://dx.doi.org/10.15578/jppi.18.2.2012.8592.

Larasati, D. A. (2011). Kajian Biologi Reproduksi Ikan Kembung Perempuan (Rastrelliger bracyosoma Bleeker, 1851) Di Perairan Teluk Jakarta, Jakarta Utara. Bogor: Departemen Manajemen Sumberdaya Perairan. Fakultas Perikanan Dan Ilmu Kelautan. Institut Pertanian Bogor.

Mananda, I. G. (2011). Studi Kelayakan Pendirian P.T. Medusa Multi Business Center (MMBC) Sumanda Tour Dan Travel Di Bali. (Kajian Aspek Pasar Dan Finansial). Bali: Program Studi Manajemen. Program Pascasarjana. Universitas Udayana Denpasar.

Nelwan, A., Sudirman, Zainudin, M., \& Kurni, M. (2015). Produktivitas Penangkapan Ikan Pelagis Besar Di Perairan Selat Makassar, Sulawesi barat. Makassar: Fakultas Ilmu Kelautan Dan Perikanan Universitas Hasanuddin.

Nurudin, F. A., Kariada, N., \& Irsadi, A. (2013). Keanekaragaman Jenis Ikan Di Sungai Sekonyer Taman Nasional Tanjung Puting Kalimantan Tengah. Unnes Journal of Life Science http://journal.unnes.ac.id/sju/index.php/Unne sJLifeSci.

Pertiwi, W. (2011). Komposisi Jenis Dan Ukuran Ikan Yang Tertangkap Dengan Sero Dan Pukat Pantai Di Perairan Kota Palopo, Provinsi Sulawesi Selatan. . Makassar: Program Studi Manajemen Sumberdaya Perairan, Jurusan Perikanan, Fakultas Ilmu 
Kelautan Dan Perikanan, Universitas Hasanuddin.

Rachma, H., Ghofar, A., \& Saputra, S. W. (2015). Studi Beberapa Aspek Biologi Ikan Bawal Hitam (Parastromateus niger) Yang Tertangkap Payang Di Kabupaten Kendal. Semantic Scholar 10.14710/MARJ.V4I4.9762.

Rahayu, N. S., Mudzakir, A. K., \& Rosyid, A. (2013). Analisis Kelayakan Finansial Usaha Perikanan Payang Jabur (Boat Seine) Di Pelabuhan Perikanan Pantai Asemdoyong Kabupaten Pemalang. . Journal of Fisheries Resources Utilization Management and Technology https://ejournal3.undip.ac.id/index.php/jfrumt /article/view/3852/3755.

Raspati, R. P. (2008). Pengkajian Hasil Tangkapan Muroami Di Kepulauan Seribu . Bogor: epartemen Pemanfaatan Sumberdaya Perikanan. Fakultas Perikanan Dan Ilmu Kelautan.

Rauf, A. ( 2012. ). Carrying Capacity. Basis Pengelolaan Terpadu Pulau-Pulau Kecil. . Makassar.: Pijar press.

Russell, D. J., \& McDougal, A. J. (2008). Reproductive Biology Of Mangrove Jack (Lutjanus argentmacuiatus) In Northeastern Queensland Australia. New Zealand Journal Of Marine And Freshwater Research. , https://www.tandfonline.com/doi/pdf/10.108 0/00288330809509950.

Shane, G., Gary, F., \& de velde, T. v. (2005). Age, Growth Reproductive Dynamics Of Talang Queenfish (Scomberoides commersonnianus) In Northern Australia. Australia: Australian Government. Department Of The Environment Heritage.

Talib, A. (2016). Keanekaragaman Fauna Non Bentik Pada Ekosistem Mangrove Disungai Tallo Kota Makassar. Makassar: Program Studi Ilmu Kelautan. Departemen Ilmu kelautan. Fakultas Ilmu Kelautan Dan Perikanan. Universitas Hasanuddin.

Tamarol, J., Luasunaung, A., \& Budiman., J. (2012). Dampak Perikanan Tangkap Terhadap Sumberdaya Ikan Dan Habitatnya Di Perairan Pantai Tabukan Tengah Kabupaten Sangihe.
Jurnal Perikanan Dan Kelautan Tropis , https://doi.org/10.35800/jpkt.8.1.2012.387.

Tuegeh, S., Tilaar, F. F., \& Manu, G. D. (2012). Beberapa Aspek Biologi Ikan Beronang (Siganus vermiculatus) Di Perairan Arakan Kecamatan Tatapaan Kabupaten Minahasa Selatan. Jurnal Ilmiah Platax, https://doi.org/10.35800/jip.1.1.2012.493.

Widiana, Setyobudiandi, I., \& Affandi, R. (2015). Biologi Reproduksi Ikan Baronang (Siganus guttatus Bloch 1787) Di Kepuluan Seribu, Jakarta. Bogor: Departemen Manajemen Sumberdaya Perairan. Fakultas Perikanan Dan Ilmu Kelautan. 